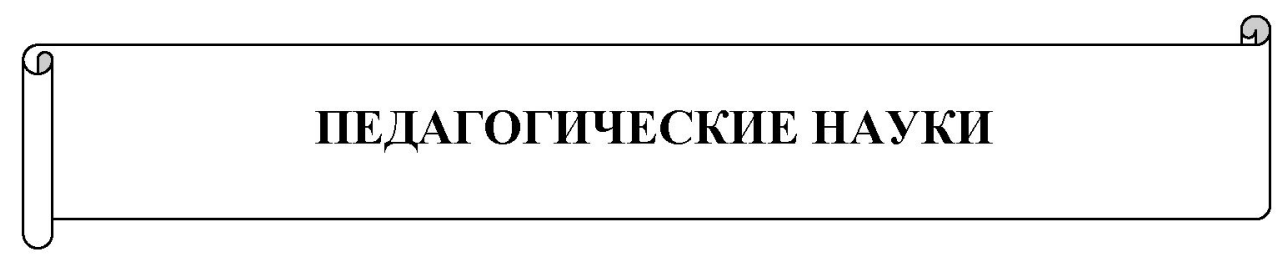

\title{
САМОСТОЯТЕЛЬНАЯ РАБОТА \\ КАК ОДНА ИЗ СОСТАВЛЯЮЩИХ ОБУЧЕНИЯ НАУЧНОМУ СТИЛЮ НА МАТЕРИАЛЕ ЯЗЫКА СПЕЦИАЛЬНОСТИ В ВОЕННОМ ВУЗЕ
}

\author{
Военный учебно-научный центр Сухопутных войск \\ «Общевойсковая академия Вооруженных Сил Российской Федерации», \\ 2. Москва, Россия
}

\begin{abstract}
Аннотация. Исследование посвящено организации самостоятельной работы иностранных специалистов в военном вузе при обучении русскому языку. Целью статьи является подготовка средств управления самостоятельной работой с учетом выполнения поставленных задач, а именно: определение роли самостоятельной работы как одной из составляющих обучения научному стилю речи; изучение лингводидактического описания внутренней организации военно-научного текста как информационной основы формирования общего блока речевой профессиональной компетенции; отбор текстового материала и разработка учебно-тренировочной и диагностико-обучающей систем заданий в четко выраженной иерархической последовательности; создание эффективных механизмов интенсивной подготовки с использованием современных компьютерных технологий и других факторов, стимулирующих мотивационный интерес обучающихся к речевому общению и организации собственной речи.

Автор подчеркивает, что в качестве средства формирования интегрированного фонда знаний, умений и навыков, необходимых для речевого профессионального общения, избрана комплексная работа с военно-научным текстом.

В статье предлагаются практические рекомендации по овладению текстовой деятельностью как под руководством преподавателя, так и в самостоятельной работе, способствующей индивидуализации обучения, самоуправлению речемыслительным интеллектуально-познавательным процессом.
\end{abstract}

Ключевые слова: терминология, коммуникативная единиия, профессионально ориентированное высказывание, термины-понятия, структурно-смысловой, логико-содержательный анализ текста. 
L. P. Bichenok

\title{
INDEPENDENT WORK AS ONE OF THE COMPONENTS OF TEACHING SCIENTIFIC STYLE BASING ON THE LANGUAGE OF THE MAJOR AT A MILITARY ACADEMY
}

\author{
Military Training and Research Centre of Ground Forces \\ "Combined Arms Academy of the Armed Forces of the Russian Federation», \\ Moscow, Russian
}

\begin{abstract}
This article is dedicated to the arrangement of independent work of foreign students of a military higher education institution when teaching Russia. The purpose of the article is the development of means of control of independent work and the fulfillment of the following tasks: to determine the role of student's independent work as one of the components of training in the scientific style of speech, the study of the linguo-didactic description of the internal organization of the military scientific text as the information ground for the formation of the general unit of speech professional competence; the selection of texts and the development of both the educational training system and the diagnostic teaching system of tasks in a clear hierarchical sequence; the creation of effective intensive training means with the use of modern computer-aided technologies and other factors, which stimulate students' motivation in communication and development of personal speech.

The author lays emphasis on the fact that that the complex work with military scientific texts was chosen as the tool for the formation of integrated fund of knowledge and skills, which are necessary for professional verbal communication.

The article provides practical recommendations on mastering of text activity both with the help of a lecturer and in terms of independent work, which contributes to a more independent learning process and self-management of a speech-thinking and intellectual-cognitive process.
\end{abstract}

Keywords: terminology, communicative unit, professionally oriented utterance, terms, structuralsemantic, logical content-related analysis of the text.

Актуальность исследуемой проблемы. Приоритетным направлением в решении задач обучения языку специальности становится самостоятельная работа как важнейшая форма творческого целенаправленного подхода к обучению, способствующему созданию познавательной мотивации и заинтересованности, а в последующем самостоятельности мышления, самоорганизации воспроизводимой и порождаемой речи, ее самоконтролю на разных этапах профессиональной подготовки. Цель исследования - обоснование значимости в учебном процессе самостоятельной работы, обеспечивающей коммуникативные потребности в формировании речевой профессиональной компетенции у иностранных военнослужащих. Источником приобретения определенных умений и навыков общения является текстовый материал информативно-познавательной сферы и среды получаемой военной специальности. Учитывая общие теоретические положения лингвистики текста, рассматриваются особенности формирования смысловой структуры текстов военных наук как текстов одной из разновидностей научного стиля речи. Под смысловой структурой текста понимается как наполнение текста научным знанием, его современным уровнем, так и языковая и речевая стороны его выражения, подчиненного законам коммуникативной сочетаемости текстообразующих элементов, позиционной закрепленности понятийно-терминологических компонентов и технологии моделирования высказывания по определенным научным конструкциям речи.

Материал и методика исследований. Значительный опыт, накопленный в области организации самостоятельной работы с иностранными военными специалистами (далее ИВС), позволил обобщить наблюдения, сделать выводы, определить лингводидактические аспекты ее дальнейшего развития, внедрить в практический процесс новые техноло- 
гии, эффективные средства и направления индивидуализации обучения и обеспечить максимальный уровень успешности образовательного процесса. Применение совокупности факторов и приемов интенсивной подготовки возможно как при использовании метода комплексного теоретического анализа научной литературы в области лингвистики, педагогики, лингводидактики, психологии, опыта и наработок преподавателей РКИ, экспертно-аналитических оценок педагогических исследований и нормативных документов, так и при выработке практической методики самостоятельного обучения в процессе структурирования, организации речевой профессиональной подготовки и ее контроля.

В начале XXI в. основной целью обучения русскому языку как иностранному является формирование языковой личности обучающегося; тем не менее, коммуникативная цель, как и принцип коммуникативности, всегда преобладает в учебном процессе, особенно при формировании навыков и умений специальной научной речи у иностранных специалистов. В качестве средства ее формирования в военной коммуникативной среде избрана комплексная работа с учебно-научным текстом как источником знаний конкретных военных сфер. Организация обучения текстовой деятельности включает многоуровневый и многоаспектный анализ профессионального текста, определение ее этапов и создание трех методически синтезированных систем: обучающей и содержательно, структурно взаимосвязанных с ней обучающе-контролирующей и контролирующей, направленных на реализацию комплексной методики работы со специальным текстом и тестовых методик контроля сформированности профессионально ориентированнных речевых навыков.

Результаты исследований и их обсуждение. Сложившиеся современные тенденции обучения русскому языку как иностранному в военном вузе предполагают формирование не только лингвистической и коммуникативной компетенции, но и особой речевой профессиональной компетенции. Это обусловлено прежде всего социальным заказом на получение военной специальности и строго определенными коммуникативными потребностями ИВС в военно-научной сфере.

«В центре современной технологии обучения находится текст, используемый комплексно: а) средство обучения русскому языку; б) источник информации; в) самостоятельная коммуникативная единица, единица общения. Текст как основа организации обучения выступает в качестве объекта языкового и структурно-смыслового анализа, образца коммуникативной деятельности и ее продукта, результата. Таким образом, комплексное и системное рассмотрение текста обеспечивает формирование коммуникативной компетенции обучаемых» $[9$, с. 160].

На основе лингвистического анализа корпуса профессионально-научного текста иностранные военнослужащие должны научиться переводить и понимать текст на русском языке, выделять и воспроизводить его основную мысль, излагать ее при ответе на вопросы и представлять в виде плана, доклада, аннотации, реферата как в устной, так и в письменной формах. ИВС должны самостоятельно не только изучать и анализировать учебно-информационный материал, но и обобщать, систематизировать его, делать выводы, определять, оценивать и отбирать научную концепцию для написания курсовых, дипломных, магистерских и, при необходимости, кандидатских работ.

Для выполнения вышеуказанных задач целесообразно использовать многоуровневый (коммуникативно-содержательный анализ, анализ текстообразующих элементовтерминов, терминологических словосочетаний) и многоаспектный (логико-понятийный и структурно-смысловой) анализ учебно-научного текста.

Комплексная работа с военно-научным текстом, состоящая из системы обучающих, обучающе-контролирующих и контролирующих заданий, позволяет создать условия для одной из важнейших форм обучения, которая на сегодняшний день занимает особое место в учебном процессе и является важным звеном методической системы обучения профессиональной речи. 
«Повышение значимости самостоятельной работы среди видов учебной деятельности обусловлено целым комплексом причин. Среди них в первую очередь называют следуюшие: разный исходный уровень готовности студентов к восприятию учебного материала по каждому предмету, различные темп, стиль, характер индивидуальной самостоятельной деятельности, различное ценностное отношение студентов к дисциплине, стремление студентов к самостоятельному структурированию своего личного времени, отражающему их индивидуально-личностные особенности» [4, с. 4].

Эффективности учебного процесса невозможно достичь лишь путем передачи знаний в готовом виде от преподавателя к слушателю. Подробные и частые объяснения преподавателя, его чрезмерная активность могут привести к торможению обучения. Эффект многократных объяснений неоднозначен, так как у слушателей возникает ложное впечатление и поверхностное представление об их собственных знаниях, поэтому они остаются внутренне пассивными и зачастую невосприимчивыми к учебному материалу.

Специфика изучения иностранного языка свидетельствует: языку нельзя научить, но можно научиться. Для этого обучающийся должен проявить максимум усилий, активности и самостоятельности во всех видах речевой деятельности. Так, отмечается, что «в мировых направлениях развития университетского образования четко проявляется тенденция роста доли самостоятельной работы студентов и смещение акцента с преподавания на учение. В этой связи становится очевидным, что с переходом на компетентностный подход в образовании необходимо формировать систему умений и навыков самостоятельной работы, воспитывать культуру самостоятельной деятельности студентов» [6, с. 4].

Что же такое самостоятельная работа? Лишь внеаудиторная работа, т. е. выполнение заданий для самостоятельного изучения и закрепления той или иной темы, или частично аудиторная работа, представляющая собой промежуточный контроль? Каков характер этой работы? Может ли она носить творческий характер либо включать имитацию и репродукцию? Какова роль преподавателя в ходе выполнения самостоятельной работы обучающимися? Эти вопросы находят отражение в определении самостоятельной работы, которые закреплены во ФГОСах и других нормативных документах. «Согласно требованиям нормативных документов, самостоятельная работа студентов является обязательным компонентом образовательного процесса, так как она обеспечивает закрепление получаемых на лекционных занятиях знаний путем приобретения навыков осмысления и расширения их содержания, навыков решения актуальных проблем формирования общекультурных и профессиональных компетенций, научно-исследовательской деятельности, подготовки к семинарам, лабораторным работам, сдаче зачетов и экзаменов» $[6$, с. 6].

Активность и заинтересованность обучающихся в самостоятельной работе возможны при условии их мотивационной, интеллектуальной, лингвистической (необходимо владеть определенным запасом лексико-грамматического материала, являющегося основой для осознанного моделирования научного высказывания) и коммуникативной готовностей. Задача преподавателя - создать условия для внутренних познавательных желаний у ИВС развивать и совершенствовать речевую инициативу в профессиональном общении, используя при этом свои интеллектуально-психологические возможности и накопленные в процессе обучения знания.

Каким способом можно достичь осознанного, творческого и целенаправленного подхода иностранных военнослужащих к самостоятельной работе?

Среди факторов, которые способствуют активизации самостоятельной работы, можно выделить ряд приемов интенсивной подготовки. Под приемами обучения понимаются «конкретные действия и операции преподавателя, цель которых - сообщать знания, формировать навыки и умения, стимулировать учебную деятельность учащихся для решения частных задач обучения〉 [1, с. 211]. 
Данные приемы реализуются при использовании активных методов игрового тренинга (в его основе лежат инновационные и организационно-деятельностные игры, деловые или ситуационные формы занятий, дискуссии, дебаты, мастер-классы, групповые обсуждения, современные компьютерные технологии, которые дают возможность использовать как готовые, так и разработанные на их основе новые учебно-информативные материалы, дополнительные упражнения с лексико-грамматическими заданиями, тренировочные тесты, тесты текущего и промежуточного контроля уровня знаний системных явлений русской грамматики, индивидуальные раздаточные материалы для самостоятельной работы). Необходимо использовать факторы, стимулирующие мотивацию контроля знаний: накопительные оценки, рейтинг, оригинальные процедуры сдачи экзаменов, зачетов, контрольных работ и тестирования; разнообразные способы поощрения ИВС за успехи в учебе и творческой деятельности; индивидуальные задания.

Все вышеперечисленные приемы интенсивной подготовки поступательно и непрерывно включаются в учебный процесс и превращают обучение в творческий процесс самостоятельного поиска знаний. При этом слушатель из пассивного наблюдателя превращается в активного участника коммуникации.

Очевидно, что на начальном этапе организация обучения самостоятельной работе возможна только в ходе практических занятий, где преподаватель с первых дней приобщает ИВС к самостоятельному труду над языком, оказывает им всестороннюю практическую помощь, управляет их учебно-познавательной деятельностью и контролирует ее осуществление.

Для успешного выполнения данных задач иностранные специалисты должны быть обучены рациональным способам усвоения лексики, грамматики и эффективным приемам овладения речевыми умениями в чтении, аудировании, говорении, письме с поэтапной сменой речевой доминанты.

Значительной поддержкой при обучении навыкам самостоятельной работы может стать использование памяток, регламентирующих правила выполнения заданий разного типа: как правильнее выполнить то или иное грамматическое задание, как лучше подготовиться к монологическому высказыванию, к составлению плана, к конспектированию и т. д. по нарастающей трудности. Памятки могут быть самого разного рода - от печатных в виде таблиц, схем, плакатов и пр. до электронных в виде закладок в электронных учебниках и пособиях и др.

Более перспективный путь обучения навыкам самостоятельной работы - создание и использование системы заданий, которая включает обучающую, структурную, содержательную, обучающе-контролирующую и контролирующую части.

На первом этапе создается система заданий на материале научного текста, который предстоит изучить и сформировать у обучающихся навыки его восприятия и воспроизведения. Эта система тренировочных заданий строится по модульному принципу, предполагает многократное применение одного и того же приема и закрепления его в аудиторные часы с последующим выполнением во внеаудиторное время.

Наиболее простыми заданиями являются задания на опознание, так как они всегда содержат ответ в виде альтернативы: «да)/〈нет». Задания на узнавание уже изученной лексики требуют нахождения наиболее полного и конкретного ответа (А, Б, В). В данном тесте неправильных ответов нет: ответы или неполной, или средней, или программной полноты.

Более сложными заданиями первого уровня являются выборочные или избирательные упражнения, а также диагностирующие задания-тесты, которые определяют уровень готовности к обучению военной специальности на русском языке. Особое место занимают задания на различение предложенных модульных вариантов и их классификацию, а также на выбор представленных терминов, совокупность которых позволяет описать 
понятие. Данные задания закладывают навыки владения лексико-семантическими и логико-понятийными особенностями военно-научного текста и понимания того, что текст представляет собой «последовательное развитие всех его подтем как основных содержательно-структурных элементов авторской концепции, при этом основными концептуальными элементами считаются научные понятия» [2, с. 13]. Термины и понятия «образуют узловые точки смысла, организуют выраженные в тексте мысли и вместе с тем определяют их границы〉 [2, с. 14]. На данном этапе самостоятельной работы возможны и целесообразны виды занятий, которые могут выполняться ИВС самостоятельно, не требуя постоянного внимания преподавателя. Это задания на нахождение терминологических единиц и частотной лексики изучаемой специальности, ознакомление с ее коммуникативной сочетаемостью и включение в многокомпонентные словосочетания. Функционируя в научном тексте, «термины вступают в сложные семантико-синтаксические отношения с другими словами, проявляют ограниченные сочетательные возможности, по-иному, нежели слова общего языка, "вживаются" в ткань текста. Все это представляет немалые трудности для обучающихся» [8, с. 355].

В основе разработанной системы лежат логические операции и лексикограмматические задания, формирующие представления о речевых, коммуникативных особенностях военно-научного текста на разных уровнях: на лексическом отрабатывается степень владения терминологической и частотной лексикой информативнообразовательного пространства; на морфологическом - степень владения активными и значимыми для военных тестов морфологическими формами и категориями; на синтаксическом - степень владения синтаксическими конструкциями, свойственными для данного подстиля научной речи.

Так как данная комплексная работа с профессиональным текстом реализуется в определенной иерархической последовательности, то следующий этап самостоятельной работы направлен на обучение приемам языковой и смысловой трансформации, синонимической замены, дополнения или конкретизации информации, уточнения того или иного выражения, что в итоге формирует у ИВС навыки полного понимания текста и его порождения. «Построение предложений подчинено определенным правилам и законам языка военной науки и соответствует научным конструкциям. Изложение научной информации носит повествовательный линейный характер, определяется синтаксической компрессией и стандартизованностью» [3, с. 29]. Обучающимся предлагается комплекс заданий по углубленной работе над предложением, микротекстом и самим текстом. Этот тип заданий способствует активизации самостоятельной работы, повышению интереса, мотивации. «Мотивация - это побуждения, вызывающие активность личности и определяющие ее направление» $[10$, с. 34$]$. В связи с этим «в основе самостоятельной деятельности при изучении русского языка как иностранного находится сознательный выбор рациональных способов творческого освоения иноязычной информации, решения поставленных учебных задач, приобретение профессиональных навыков и умений» [7, с. 34].

Ко второму уровню относятся задания, требующие самостоятельного создания (конструирования) ответа. Например: допииите (распространите) определение; составьте словосочетания по моделям: прил. + сущ. (позищионная оборона), сущ. + сущ. в P. п. (район обороньі), суи. + суи. + сущ. в P. п. (замысел действий командира); составьте текст, используя набор слов в лексической справке; составьте возможные словосочетания со словом «опасность».

Также активно используются типовые упражнения на подстановку, в текстах которых намеренно пропущены слово, словосочетание или другой какой-либо существенный элемент. Например: вставьте необходимый по смыслу термин или терминологическое словосочетание: 
.. есть собственный инструмент государства, его неотъемлемый составной элемент.

Эталон: Вооруженные Силь есть собственный инструмент государства, его неотьемлемый составной элемент.

К заданиям такого типа относится многоуровневый тест, который включает пять позиций вставок: вставьте термины-существительные; глаголь-сказуемьле или краткие причастия-сказуемые; определения (прилагательные, причастия, порядковые числительные); вставьте дополнения, обстоятельства; терминологическое словосочетание. Содержание и количество вставок может изменяться в зависимости от решения коммуникативных задач.

Часто для текушего (промежуточного) контроля используются типовые задачи, то есть задачи, условия которых позволяют «с места) применять известное правило, формулу, научную конструкцию, схему и т. д. и получить необходимый ответ на поставленный в задаче вопрос. Например, прочитайте фрагмент текста и найдите определение понятия «оборона». Дайте определение понятия «оборона», используя следующие конструкции научного стиля речи: что - это что; что представляет собой что; что является чем; под чем понимается (подразумевается) что.

Далее выполняются тесты на воспроизведение научного текста с разноуровневыми заданиями.

Составьте текст «Назначение и главные задачи военной политики», используя лексическую справку:

Назначение, главные задачи, военный, политика, это, создание, формирование, военныци, сила, регулирование, она, состав, и, уровень, применение, военный, сила, в(во), имя, политические, цели, внутри, страна, и, на, международный, арена. Эталон: Назначение и главные задачи военной политики - это создание, формирование военной силы, регулирование ее состава и уровня, применение военной силь во имя политических иелей внутри страны и на международной арене.

Определить уровень понимания содержания научного текста, его полноту, глубину и границы смысловых частей, умения логически излагать содержание текста, а также проверить долговременную память при восприятии текста, догадки, навыки синтаксических и синонимических замен позволяет многоуровневый вопросный тест, тестовое содержание которого вариативно. Приведем пример вопросного теста.

1. Прочитайте текст, составьте вопросы к тексту. Запииите.

2. По характеру ответов предложите вопросы к ним. Запииите.

3. Распределите пункты плана в соответствии с логикой развития содержсания текста. Запииите номера вопросов.

4. Допииите вопросы, вставыте опорные (ключевые) слова.

5. Переведите вопросный план в назывной. Запииите.

6. Переведите вопросный план в тезисный. Запииите.

7. Составьте вопросы к содержсанио текста, определяющего понятия.

8. Cоставьте вопросы на оравнение и сопоставление понятий, представленных в тексте.

9. Составьте вопросы на выделение классификационных признаков понятия, представленных в пексте.

10. Составьте вопросы на обобщение информации о понятии по суцественным несуиественным признакам, представленным в тексте.

Как мы видим, задания второго уровня являются не только контролирующими, но в большей степени обучающими и используются в основном для текущего поэтапного контроля, формирования речевой профессиональной компетенции. 
Чтобы добиться максимального успеха в воспроизводстве и полном порождении профессионально ориентированного текста, разрабатывается методика работы с таблицами, диаграммами, графиками, синтаксическими моделями, логико-структурными схемами и их заполнением, логико-понятийными конструкциями и матрицами, смысловыми блоками, классифицирующими существенные и несущественные признаки понятий, на основе которых предлагается устный или письменный пересказ научного текста, вычленение основной информации, смысловых частей, озаглавливание их, составление номинативного плана, выделение тезиса, доказательств.

Далее в системе обучения следует задание-изложение, выполнение которого определяет уровень понимания и воспроизведения текста.

Для создания реальных условий использования знаний практической деятельности ИВС разрабатывается комплекс типовых упражнений третьего уровня, предполагающий творческий вид самостоятельной работы. Это задания на создание (порождение) текста по ряду учебных тем, выражение уже собственных мыслей, моделирование и продуцирование высказывания, соответствующего решению реальной ситуативно-речевой задачи.

При выполнении системы заданий обучаемый самостоятельно должен выбрать номинальные и реальные определения понятия; дать определение понятия по классификационным признакам; обобщить информацию, т. е. написать самостоятельно текст, соответствующий теме, идее, объему содержания, логике изложения и учета специфики структурно-содержательных компонентов военно-научного текста.

Возможны следующие варианты заданий: выберите фактическую информацию из содержсания текста; сделайте правильный выбор; отвечает ли данный текст на вопрос: «...?»; какое утверждение дополняет основную информацию; выберите правильный ответ при формулировке понятия (умозаключения, вывода и т. д.); выберите тот вариант ответа, который в больией степени соответствует основному содержсанию текста.

Так, управление самостоятельной работой со временем перерастает в контролирующую функцию преподавателя. Преподаватель, поочередно выбирая одного из обучающихся группы, контролирует понимание им информационного поля текста, проверяет усвоение лексико-грамматического материала, дает необходимые консультации, остальные работают самостоятельно или в парном режиме.

Организуя самостоятельную работу, преподаватель должен иметь в виду, что она в учебных условиях является лишь относительно самостоятельной. Даже обучающиеся с высоким уровнем языковой компетентности испытывают на себе косвенное воздействие преподавателя на протяжении всего учебного процесса.

Формируя навыки самостоятельной работы, преподаватель использует симбиоз трех общепринятых форм обучения - фронтальную, групповую и индивидуальную с опорой на групповую форму обучения. «Основной задачей групповой формы аудиторной работы является организация дискуссии и ролевых игр таким образом, чтобы каждый студент мог бы присоединиться к обсуждению, активно участвовать в нем и стать равноценным партнером в команде, что в конечном итоге приведет к росту уровня его знаний и усвоению русского языка» [5, с. 115].

Умения учащихся ориентироваться и принимать решения в новых, проблемных ситуациях выявляются при выполнении заданий четвертого уровня. Создание таких заданий - сложная задача, так как требует от преподавателя учитывать уровень учебных достижений - стандарт, стратегию обучения, диагностические трудности, социальный отбор, особенность создания системы заданий и методики организации самостоятельной работы в аудиторное время; измерение учебных достижений, нормы, индивидуальные результаты.

Обучаемый должен показать умения создавать монологические высказывания, подготовить аннотацию, реферат по заданной теме, научный обзор по темам и проблемам, 
актуальным в обучении военной специальности, владеть логическими операциями определения, сравнения, сопоставления, классификации, компрессии, редактирования и обобщения информации об определенных военно-научных понятиях: основная форма тактических действий; теория и практика подготовки и ведения военных действий; основы обороны; военная мощъ государства.

Обучение монологическому высказыванию может приобретать различную форму и жанровую направленность. Приведем примеры заданий.

1. Напииите сообщение о реформах ВС РФ. Каждое ваме предложение должно быть аргументировано.

2. Напииите текст (объяснительную записку, письмо-запрос) в соответствии с представленной ситуацией: а) реорганизация $B C$; б) формирование $B C$; в) дислокация $B C$; г) передислокаиия $B C$.

3. Подготовьте научный обзор по теме «Характер задач военной политики».

4. Подготовьте доклад на тему «Военная моцьь и военная организация государства, их взаимосвязь с политикой» и изложсите ваиу точку зрения по этому вопросу.

5. В прочессе дискуссии по проблеме «Сочиально-политические основы конщепчии национальной безопасности и военной доктрины России» выскажите свою точку зрения, приведите веские аргументы «за» и «против». Включите в ваме сообщение иллюстративный материал.

6. Подготовьте реферативное сообиение по теме магистерской диссертачии «Особенности обеспечения надежной работы инженерной техники в боевых условиях».

Резюме. Таким образом, разработанный учебно-методический блок комплексной работы с военно-научным текстом (многоуровневый и многоаспектный анализ) представляет собой конкретную реализацию обучения профессионально ориентированной речи ИВС. Обучающие, обучающе-контролирующие и контролирующие задания, новые приемы интенсивной подготовки и современные компьютерные технологии являются резервом для совершенствования методики организации и управления самостоятельной работой как одной из составляющих обучения научному стилю на материале языка специальности. Выбор лингводидактического аспекта речевой подготовки в структуре учебного процесса позволил определить условия и механизмы формирования и диагностики конкретных коммуникативно-профессиональных компетенций будущих военных специалистов высшей квалификации.

\section{ЛИТЕРАТУРА}

1. Азимов Э. Г., Цукин А. Н. Новый словарь методических терминов и понятий (теория и практика обучения языкам). - М. : ИКАР, 2009. - 448 с

2. Бидайбеков E. Ы., Корнилов В. С., Камалова Г. Б. Применение компьютерных технологий при обучении студентов вузов обратным задачам для обыкновеных дифференциалыых уравнений // Вестник РУ ДН. Серия: Информация образования. - 2015. - № 2. - С. 57-72.

3. Биченок Л. П. Обучение военной профессиональнй речи. Тестовые формы контроля : автореф. дис. ... канд. пед. наук : 13.00.02. - М., 2000. -25 с.

4. Биченок Л. П. Текст по специальности: методнка проведения учебного занятия с иностранными военнослужащими // Научный вестник Воронежского архитектурно-строительного университета. Серия: Лингвистика и межкультурная коммуникация. - 2016. - № 1(20). - С. 27-33.

5. Гугина E. B., Кузенков O. А. Организация самостоятельной работы студентов в Нижегородском государственном университете им. Н. И. Лобачевского : методические рекомендации. - Н. Новгород : Изд-во НГУ, 2012. $-47 \mathrm{c}$.

6. Дэн Цзе, Бурлакова И. И. Формирование коммуникативной компетенции у обучающихся с использованием групповой формы аудиторной работы // Русский язык за рубежом. - 2019. - № 4. - С. 113-117.

7. Меренков А. В., Куньииков С. В., Гречухина Т. И., Усачева А. В., Вороткова И. Ю. Самостоятельня работа студентов: виды, формы, критерии оценки : учебно-методическое пособие. - Екатеринбург : Изд-во Уральского университета, 2016. - $80 \mathrm{c}$. 
8. Мещерякова Б. Г., Зинченко В. П. Болышой психологический словарь. - М. : Прайм-Еврознак, 2003. $-672 \mathrm{c}$.

9. Москалева М. М. Принципы отбора лексики // Преподавание русского языка как иностранного в вузе: традиции, новации, перспективы. - М. : Изд-во МГИМО, 2018. - С. 354-360.

10. Токарева T. E. Формирование коммуникативной компетенции как основа обучения военнослужащих из СНГ // Обучение иностранных специалистов в вузах: проблемы, тенденции, решения : материалы всероссийской научно-практической конференцин. - Тверь : Военный университет противовоздушной обороны, 1999. - C. 159-162.

Статья поступила в редакцию 28.10.2019

\section{REFERENCES}

1. Azimov E. G., Shcukin A. N. Novyj slovar' metodicheskih terminov i ponyatij (teoriya i praktika obucheniya yazykam). - M. : IKAR, 2009. - $448 \mathrm{~s}$.

2. Bidajbekov E. Y., Komilov V.S., Kamalova G. B. Primenenie komp'yuternyh tekhnologij pri obuchenii studentov vuzov obratnym zadacham dlya obyknovennyh differencial'nyh uravnenij // Vestnik RUDN. Seriya: Informaciya obrazovaniya. - 2015. - № 2. - S. 57-72.

3. Bichenok L. P. Obuchenie voennoj professional'noj rechi. Testovye formy kontrolya : avtoref. dis. ... kand. ped. nauk : 13.00.02. - M., 2000. $-25 \mathrm{~s}$.

4. Bichenok L. P. Tekst po special'nosti: metodika provedeniya uchebnogo zanyatiya s inostrannymi voennosluzhashchimi // Nauchnyj vestnik Voronezhskogo arhitekturno-stroitel'nogo universiteta. Seriya: Lingvistika i mezhkul'turnaya kommunikaciya. - 2016. - № 1(20). - S. 27-33.

5. Gugina E. V., Kuzenkov O. A. Organizaciya samostoyatel'noj raboty studentov v Nizhegorodskom gosudarstvennom universitete im. N. I. Lobachevskogo : metodicheskie rekomendacii. - N. Novgorod : Izd-vo NGU, 2012. $-47 \mathrm{~s}$.

6. Den Cze, Burlakova I. I. Formirovanie kommunikativnoj kompetencii u obuchayushchihsya s ispol'zovaniem gruppovoj formy auditomoj raboty // Russkij yazyk za rubezhom. - 2019. - № 4. - S. 113-117.

7. Merenkov A. V., Kun'shchikov S. V., Grechuhina T. I., Usacheva A. V., Vorotkova I. Yu. Samostoyatel'naya rabota studentov: vidy, formy, kriterii ocenki : uchebno-metodicheskoe posobie. - Ekaterinburg : Izd-vo Ural'skogo universiteta, 2016. - $80 \mathrm{~s}$.

8. Meshcheryakova B. G., Zinchenko V. P. Bol'shoj psihologicheskij slovar'. - M. : Prajm-Evroznak, 2003. - 672 s.

9. Moskaleva M. M. Principy otbora leksiki // Prepodavanie russkogo yazyka kak inostrannogo v vuze: tradicii, novacii, perspektivy. - M. : Izd-vo MGIMO, 2018. - S. 354-360.

10. Tokareva T. E. Formirovanie kommunikativnoj kompetencii kak osnova obucheniya voennosluzhashchih iz SNG // Obuchenie inostrannyh specialistov v vuzah: problemy, tendencii, resheniya : materialy vserossijskoj nauchno-prakticheskoj konferencii. - Tver' : Voennyj universitet protivovozdushnoj oborony, 1999. - S. 159-162.

The article was contributed on October 28, 2019

\section{Сведения об авторе}

Биченок Людмила Павловна - кандидат педагогических наук, доцент кафедры русского языка Военного учебно-научного центра Сухопутных войск «Общевойсковая академия Вооруженных Сил Российской Федерации», г. Москва, Россия; e-mail: bichenok_1@,bk.ru

\section{Author information}

Bichenok, Lyudmila Pavlovna - Candidate of Pedagogics, Associate Professor of the Department of Russian Language, Military Training and Research Centre of Ground Forces «Combined Arms Academy of the Armed Forces of the Russian Federation», Moscow, Russia; e-mail: bichenok_l@bk.ru 